\title{
SPECIFICS OF THE DISTRIBUTION SERVICES AND
} MARKET POSITION OF SOPHARMA TRADING AD

\author{
Galina Petrova $^{1}$, Todorka Kostadinova ${ }^{1}$, Stanislava Yordanova ${ }^{2}$ \\ ${ }^{1}$ Department of Economics and Healthcare Management, Faculty of Public Health, \\ Medical University of Varna, Bulgaria \\ ${ }^{2}$ Master of Pharmaceutical management, Medical University of Varna, Bulgaria
}

\begin{abstract}
The distribution solutions, which are part of the distribution and logistics policy of Sopharma Trading AD, play a key role for the overall success of the company. Distribution in itself is an important element that takes time to build and represents a strong corporate linking with multiple intermediaries. Creating effective distribution channels is so crucial that it can predetermine the outcome of competition between companies. In this article are presented the distribution services and solutions, as well as the market position of Sopharma Trading AD.
\end{abstract}

Keywords: distribution policy, distribution solutions, trade, medicines

\section{INTRODUCTION}

Distribution policy is a key factor for achieving the company goals and a continuation of the ideas underlying the marketing strategy, i.e. possibly the fullest and greatest customer satisfaction. The main objective of the distribution policy is to ensure the movement of goods from the manufacturers to the customers at minimum expenses. This directly links distribution with the economic concept for better supply management, resource saving and cuts in the total expenses for servicing the delivery of the prod-

\footnotetext{
Address for correspondence:

Galina Petrova,

Faculty of Public Health,

Department of Economics and Healthcare Management

Medical University of Varna

55 Marin Drinov Str.

9002 Varna, Bulgaria

e-mail:gal_rumenova@abv.bg
}

Received: April 01, 2015

Accepted: June 04, 2015 ucts and their sale at a competitive price. The purpose of the distribution policy is to organise the system for product distribution in an optimal way. "Distribution creates favourable opportunities for the proper products to be at a particular place, at a particular time at competitive prices" (1).

THE OBJECTIVE of this study is to analyse the main attributes and specifics of the distribution policy of Sopharma Trading AD.

\section{MATERIALS AND METHODS}

The methodological approach to the subject includes document analysis. The materials that are used are company reports and data from IMS Health Bulgaria, regarding the distribution policy of Sopharma Trading AD.

\section{General description of the company}

Sopharma Trading AD is a joint stock company registered in Bulgaria under the Commerce Act. The main activity of Sopharma Trading AD is wholesale and retail trade in medicinal products, sanitary and hygiene products, food supplements and cosmetics at 
a total of more than 700 items. With its five Regional Distribution Centres the company has a $100 \%$ national coverage. It supplies 3500 pharmacies and 350 healthcare facilities. Sopharma Trading AD offers a pre-distribution service: storage and logistic services of pharmaceutical products as well as a variety of marketing services for Bulgarian and foreign manufacturers and importers of medicinal products $(2,4)$.

The company's revenue consists of the income from product sales, sale of medical equipment and revenue from pre-distribution services, marketing and other services. Sopharma Trading AD operates under one-tier management system which is governed by a board of directors of three members. On the territory of the Republic of Bulgaria the company has five Regional Distribution Centres respectively in the cities of Sofia, Varna, Burgas, Plovdiv and Veliko Tarnovo thus providing 100\% coverage of the country. Sopharma Trading AD is founder of the Bulgarian Association of Pharmaceutical Wholesalers (4).

\section{Market position}

All sales of Sopharma Trading AD are performed on the territory of Bulgaria. The company realises sales in two market segments - pharmacies and hospitals. Two commercial teams function within the market of pharmacies: General Portfolio and Featured Products. In the hospital segment there are three sales divisions: Medicinal Products, Consumables, Medical devices and equipment. In addition to the distribution of products to retailers Sopharma Trading AD sells medicinal products to other wholesalers and provides services such as storage and logistics $(2,3)$.

Distribution of medicinal products is continuing to consolidate. The top four companies serve $81.84 \%$ of the pharmaceutical market, due to the compactness of their activity. The market share of Sopharma Trading AD from the pharmaceutical market based on IMS Health data for 2012 is $21.6 \%$, and by 06.2013 it is $22.05 \%$. The market share of Sopharma Trading AD for 2012 in terms of value is $19.5 \%$ for the pharmacy market and $35.3 \%$ for the hospital market.

Sopharma Trading AD is a leader in the hospital market segment and realises growth in sales. The determining factors being financial stability of the company, the ability to meet the needs for funding of the sector, as well as good relationships with manufacturers. A huge impact is also made by the good positions gained at decentralised tenders for expensive medicinal products $(2,3)$.

Despite the highly competitive environment, in 2012 Sopharma Trading AD succeeded in keeping it is leading position on the Bulgarian pharmaceutical market with a market share of 21.6\% (Fig.1). After the investments in logistics, marketing services and programmes, where customer satisfaction is leading, an increasing number of manufacturers and pharmaceutical companies identify Sopharma Trading $\mathrm{AD}$ as the most reliable and professionally working distributor and approach the company with offers for joint programmes focused on improvement in the quality of life of the Bulgarian patient.

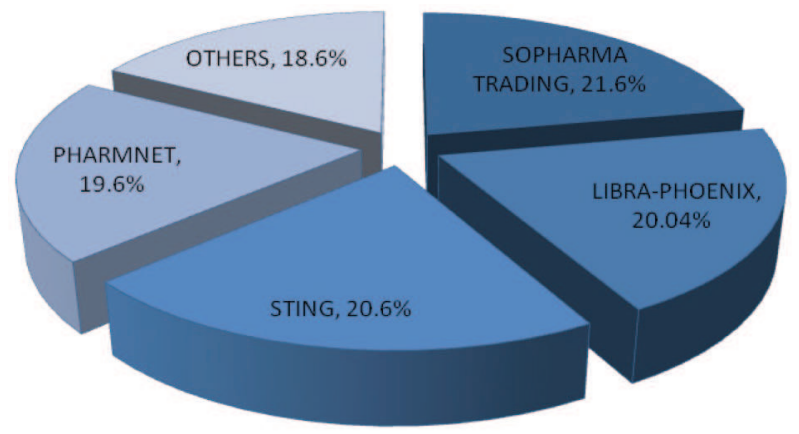

Fig. 1. Value market share of distribution companies from the total pharmaceutical market for 2012

${ }^{*}$ Data from IMS Health Bulgaria

Determinants of the good results of Sopharma Trading $\mathrm{AD}$ are the continuing market growth and the diversification of both the product portfolio and the customers' channels. Increasing the revenue and retaining and growing customers are interdependent on faster deliveries, better services and better prices through effective logistics. Sopharma Trading AD is a progressive distribution company which constantly seeks ways to satisfy the changing needs of customers as well as to add value to the target corporate clients (2).

Sopharma Trading AD sells both locally manufactured products and imported ones (chiefly from EU countries). Imported products dominate and their relative share has reached $80 \%$ by June 2013 . Sopharma Trading AD can follow the market trends and keep good business relationships with all manu- 
Specifics of the Distribution services and market position of Sopharma Trading AD

facturers on the Bulgarian market rather than exert influence on this distribution of sales.

The sales structure of Sopharma Trading AD, with small exceptions, corresponds with the classification of the manufacturers on the pharmaceutical market. Top 20 of the manufacturers of medicinal products make up $56 \%$ of the total market sales in 2012 whereas in the sales structure of Sopharma Trading AD, these manufacturers account for $57 \%$ of sales. These scores are the result of purposeful and consistent work of the company with all leading pharmaceutical manufacturers present on the Bulgarian market $(3,4)$.

\section{Distribution services}

The main efforts for change in the business processes are towards optimisation and increase in the quality of the distribution policy. At present the customer service stages are: (1) taking orders, (2) picking from the warehouse, (3) delivery to the customer's premises, (4) collecting payments due from customers. Within the market environment, customer satisfaction with the distribution quality plays a strategic role in achieving a leading market position. This factor incorporates (1) accuracy, promptness and expertise of the employees accepting phone orders, (2) cancellations, (3) match between invoice amount and batch amount, (4) timely delivery according to the transport schedule, (5) quick processing of recalls. In this context Sopharma Trading AD chiefly aims at stability and predictability of the distribution service at an optimal price.

$A D$

Other services provided by Sopharma Trading

* Pre-distribution - storage and logistic servicing of pharmaceutical products of Bulgarian and foreign companies. Apart from the standard logistic services, such as storage, the company provides services specific for the pharmaceutical business such as storage of temperature-sensitive products, destruction of medicinal products, a package of financial services, logistic management of clinical trials and others.

* Logistic services for companies conducting clinical trials in Bulgaria. The services include delivery and storage of trial products as well as all procedures connected with their withdrawal and destruction.
* Marketing and advertising services for manufacturers - Sopharma Trading AD offers publishing contracts for its free monthly customer newsletter which is spread among owners of pharmacies and pharmacists. It specialises in providing useful information about the pharmaceutical business, medicinal and non-medicinal products. The company offers a varied portfolio of marketing services and initiatives for partner suppliers and manufacturers to help them promote their products on the Bulgarian pharmaceutical market.

* Renting of tangible fixed assets - for some of its exclusive partners Sopharma Trading AD offers part of its logistics potential to rent (2).

The main advantages of distribution system of Sopharma Trading AD involve the following:

1. An automated system for handling and storage of goods was adopted in the regional distribution centre in Sofia. Logistics warehouses were built in Plovdiv and Veliko Tarnovo.

2. Improved the quality of the website for online ordering so as to create the best working environment for the customers, provide additional information and services through the website and encourage them to use this communication channel.

3. Increased dealers' efficiency and guaranteed connectivity for customers. Introduced fixed time periods for taking orders from clients.

4. Reduced the time for processing of recalls and established feedback mechanisms for all registered cases.

5. Reduced number of order cancellations mainly through changing the delivery methodology and by establishing a Planning and Forecasting Unit.

6. Increased the number of vehicles and delivery destinations.

7. Encouraged the use of bank transfers in order to ensure better transportation safety and efficiency of deliveries.

\section{FINDINGS}

1. Sopharma Trading AD steadily sticks to a strategy of renovating its portfolio with medicinal products with guaranteed quality and long-standing use. 
2. The company disposes of a broad network of affiliates both on the territory of the country and worldwide.

3. The main objective of the distribution policy is to spread its positions on the existing markets and penetrate new markets.

\section{CONCLUSION}

Sopharma Trading AD is one of the leading distribution companies of medicinal products, medical consumables, sanitary and hygiene products, vitamins, food supplements and cosmetics. The company meets the international requirements and European standards. It is one of the major and preferred partners for clients, suppliers, manufacturers and investment partners. In order to maintain its leading position in sales of medicinal products and to increase the market share, the company invests in the launch of innovative technical and technological solutions.

\section{REFERENCES}

1. Kantardzhiev H., Distribution, Economy - University Publishing House, Sofia, 2008

2. Financial Report of Sopharma Trading AD, 2012

3. Data from IMS Health Bulgaria

4. www.sopharmatrading.bg 